\title{
Research on the Impact of Chinese Digital Inclusive Finance on Industrial Structure Upgrade-Based on Spatial Dubin Model
}

\author{
Mingyang Liang \\ Jinan University, Guangzhou, China \\ Email: 422746616@qq.com
}

How to cite this paper: Liang, M.Y. (2020) Research on the Impact of Chinese Digital Inclusive Finance on Industrial Structure Upgrade-Based on Spatial Dubin Model. Open Journal of Statistics, 10, 863-871. https://doi.org/10.4236/ojs.2020.105050

Received: September 30, 2020

Accepted: October 27, 2020

Published: October 30, 2020

Copyright (๑) 2020 by author(s) and Scientific Research Publishing Inc. This work is licensed under the Creative Commons Attribution International License (CC BY 4.0).

http://creativecommons.org/licenses/by/4.0/

\section{(c) (i) Open Access}

\begin{abstract}
Based on the panel data of 30 provinces, municipalities, and autonomous regions in China from 2011 to 2018, this paper uses the digital inclusive financial index and industrial structure upgrading coefficient of the Internet Research Center of Peking University as the core explanatory and explained variables to construct a spatial panel. Bin model performs regression analysis on the effect of digital inclusive finance in the upgrading of industrial structure. The results prove that the development of digital inclusive finance in this province and city has significantly promoted the upgrading of the regional industrial structure, and it has a positive overall effect on the upgrading of industrial structure.
\end{abstract}

\section{Keywords}

Industrial Structure Upgrade, Chinese Digital Inclusive Finance, Spatial Dubin Model

\section{Introduction}

Inclusive finance aims to provide appropriate and effective financial services for all sectors of society that need financial services based on the principles of equal opportunity and business sustainability. In recent years, with the development of digital technology, digital inclusive finance that relies on information technology, big data technology and cloud computing has emerged, further expanding the concept and practice of inclusive finance. Due to the problem of financial exclusion in traditional finance, its function of serving the real economy cannot be played well. Digital inclusive finance is to provide digital financial service channels for groups excluded from the formal traditional financial system and 
unable to enjoy financial services, including online payment, transfers, credit, savings, insurance, and securities, to meet the financial needs of service targets. Compared with traditional inclusive finance, digital inclusive finance uses digital technology to screen financial risks to reduce information asymmetry, and can efficiently provide quality services to small, medium and micro enterprises and low-income groups.

Xing Yan (2015) [1] believes that inclusive finance breaks the restriction of traditional financial exclusion and makes a great contribution to social development and economic growth. He Dexu (2015) [2] believes that inclusive finance can improve financial inclusion, provide fair financing opportunities for projects with valuable and contribution to social development, and improve resource efficiency. Xie Ping (2015) [3] believes that because digital inclusive finance has the characteristics of reducing information asymmetry and lowering transaction costs, it helps to achieve transaction disintermediation and optimal allocation of resources. Sun Jie (2017) [4] believes that the Internet finance developed by mobile payment, cloud computing, big data and other technologies has broken the monopoly of banks and can play a more effective role in finance and optimize resource allocation. Bai Xinxian and Zhang Kun (2017) [5] believe that inclusive finance optimizes asset allocation through its coverage and promotes the upgrading of industrial structure. Yuan Haidong (2018) [6] believes that inclusive finance lowers the threshold of financial services, improves the efficiency of resource allocation, promotes technological innovation of small, medium and micro enterprises, supports the development of disadvantaged industries, and promotes the upgrading of industrial structure. Fu Qiuzi (2018) [7] found that the more developed the digital Inclusive Finance, it can reduce the demand for rural productive formal finance and promote the growth of consumer credit. Tang Wenjin et al. (2019) [8] believe that digital inclusive finance can generate positive externalities for the upgrading of industrial structure through capital formation, factor allocation, demand effects and technological progress effects. Cao Kaiyan (2019) [9] found that the impact of digital Inclusive Finance on the upgrading of industrial structure has regional heterogeneity, and it has a significant role in promoting the eastern and western provinces of China. Guo Feng (2020) [10] compiled the data of digital Inclusive Finance using the data of a representative digital financial institution from 2011 to 2018, and found that China's digital Inclusive Finance showed strong regional convergence characteristics, and had spatial clustering and spatial heterogeneity. Guo Wanli (2020) [11] found that the development of digital inclusive finance can significantly promote the upgrading of China's industrial structure, and its different dimensions have different promoting effects on the upgrading of industrial structure. Su Rengang (2020) [12] found that Inclusive Finance has significantly promoted the upgrading of China's industrial structure, in which the development of the Internet has a regulatory effect and intermediary effect.

At present, there are abundant theoretical studies on the impact of digital Inclusive Finance on the upgrading of industrial structure, but more articles are 
based on the traditional panel model, and less on the spatial spillover effect between digital inclusive Finance and industrial structure optimization from the perspective of spatial correlation. Therefore, based on the existing research, this paper uses spatial econometric model to study the relationship between digital Inclusive Finance and industrial structure upgrading in China, and explores the correlation between them from the perspective of space.

\section{Model Construction and Data Description}

\subsection{Model Construction}

At present, spatial measurement mainly spatial Dubin model (SDM). According to Elhorst (2014), the spatial Dubin model is a suitable spatial model. This paper chooses the spatial Dubin model to perform regression analysis on related variables. The final regression model is:

$$
\ln \mathrm{IS}=\rho W \ln \mathrm{IS}+\beta X+\theta X W+\varepsilon
$$

where $W$ is the spatial weight matrix, this article uses the geographical distance weight matrix and performs row standardization processing; IS represents the industrial structure, $X$ represents the explanatory variable vector group, including core explanatory variables and control variables, $\rho$ is the spatial autocorrelation coefficient, and $\theta$ is the space The spillover coefficient, $\varepsilon$ is the spatial error term.

\subsection{Indicator Description}

- The explained variable

Industrial structure upgrading coefficient: According to Crick's law, as the per capita national income of society increases, the employed population shifts from the primary industry to the secondary industry, and finally to the tertiary industry. This article draws on the methods of Lan Qingxin (2013) and Xu Min (2015) to measure the upgrading of the industrial structure of 30 provinces, municipalities and autonomous regions in China from 2011 to 2018. The specific formula is:

$$
\mathrm{IS}_{i t}=\sum_{n=1}^{3} n x_{i t n}
$$

$x_{n}$ represents the ratio of the $n$-th industry's added value to GDP. The larger the value of IS, the higher the level of industrial structure. The relevant data comes from the "China Statistical Yearbook".

- Core explanatory variables

Index of Digital Inclusive Finance (IFI): This article draws on the Peking University Digital Financial Inclusive Index (2011-2018), which builds a digital financial inclusive system from the three dimensions of digital financial inclusive service coverage, depth of use, and digitalization.

- Other control variables

Regional GDP per capita (pgdp): Regional economic development is an important driving force for the upgrading of industrial structure. This paper uses 
per capita GDP to measure the level of economic development

Openness coefficient (open): The degree of opening up of a region to the outside world will affect the allocation of resources in the region and thus have an effect on the upgrading of the industrial structure. In this paper, the total import and export volume of each province, municipality, and autonomous region is divided by the gross domestic product to measure the degree of opening up of each region.

$$
\text { open }=\frac{\text { Regional Total Import and Export }}{\text { GDP }}
$$

Degree of government intervention (gov): The influence of government intervention on the adjustment and upgrading of the industrial structure cannot be ignored. Government fiscal expenditure can act on the optimal allocation of resources in the region and promote the upgrading of the industrial structure. Unreasonable intervention will lead to waste of resources and is not conducive to the upgrading of the industrial structure. This article uses the fiscal expenditure of each province, municipality, and autonomous region divided by the GDP to measure the degree of government intervention in each region.

$$
\text { gov }=\frac{\text { Regional Fiscal Expenditure }}{\text { GDP }}
$$

The above data comes from the China Statistical Yearbook and the statistical yearbooks of various provinces and cities. Among them, due to the lack of Tibet data, it is not included in the analysis scope of the empirical model (Table 1).

\section{Spatial Measurement Inspection and Result Analysis}

\subsection{Spatial Correlation Analysis and Measurement Model Test}

Before conducting the spatial empirical analysis, we first test the spatial correlation of the industrial structure upgrading coefficients between provinces, municipalities and autonomous regions, and use the Moran's I index as a measure of the global spatial correlation. The formula of Moran's I index is as follows:

$$
I=\frac{\sum_{i=1}^{n} \sum_{j \neq i}^{n} \omega_{i j}\left(y_{i}-\bar{y}\right)\left(y_{j}-\bar{y}\right)}{S^{2} \sum_{i=1}^{n} \sum_{j=1}^{n} \omega_{i j}}
$$

\begin{tabular}{|c|c|c|c|c|c|}
\hline Variable & meaning & Mean & $\begin{array}{c}\text { Standard } \\
\text { Deviation }\end{array}$ & Minimum & $\operatorname{Max}$ \\
\hline is & Industrial structure upgrading coefficient & 2.36063 & 0.127254 & 2.166332 & 2.827268 \\
\hline Ifi & Index of Digital Inclusive Finance & 188.185 & 84.97971 & 18.33 & 377.7338 \\
\hline pgdp & Regional GDP per capita & 52736.1 & 25007.93 & 16413 & 153095 \\
\hline open & Openness coefficient & 1746775 & 3092561 & 37600 & $2.11 \mathrm{E}+07$ \\
\hline gov & Degree of government intervention & 0.27912 & 0.312265 & 0.016808 & 1.548163 \\
\hline
\end{tabular}

Table 1. Variable descriptive statistics table. 
Among them, $S^{2}$ is the sample variance, $y_{i}$ represents the observation value of the $i$-th area, $n$ is the total number of areas, and $\omega_{i j}$ is the weight matrix of the geographical adjacency space. Table 2 shows the Moran's I index of industrial structure upgrade.

Table 2 shows that the Moran'I index for the upgrading of the industrial structure of various regions in China country is positive, and all have passed the $1 \%$ significance test. It shows that the industrial structure upgrading coefficients of various regions in China country show a significant positive spatial correlation.

\subsection{Analysis of Model Results}

The estimated results of the spatial Dubin model are shown in Table 3. From the results in the table, the direct impact of the digital inclusive finance index on the upgrading of the industrial structure is positive and significant, indicating that digital inclusive finance can play a significant role in the upgrading of the regional industrial structure enhancement. In the time-fixed model, the digital

Table 2. Moran's I index of Chinese industrial structure upgrading coefficient index.

\begin{tabular}{cccc}
\hline Year & Moran's I & Z Value & P Value \\
\hline 2011 & 0.347 & 4.008 & 0.000 \\
2012 & 0.401 & 4.619 & 0.000 \\
2013 & 0.378 & 4.404 & 0.000 \\
2014 & 0.380 & 4.432 & 0.000 \\
2015 & 0.326 & 3.856 & 0.000 \\
2016 & 0.365 & 4.283 & 0.000 \\
2017 & 0.374 & 4.386 & 0.000 \\
2018 & 0.396 & 4.580 & 0.000 \\
\hline
\end{tabular}

Table 3. Regression results of spatial Dubin model.

\begin{tabular}{ccccccc}
\hline & \multicolumn{2}{c}{ Spatial fixed effects } & \multicolumn{2}{c}{ Time fixed effect } & \multicolumn{2}{c}{ Both fixed effect } \\
\hline Variable & Coefficient & P Value & Coefficient & P Value & Coefficient & P Value \\
\hline Ifi & 0.0002832 & 0.120 & 0.0007055 & 0.000 & 0.0002733 & 0.095 \\
lnpgdp & -0.0520333 & 0.000 & 0.0225609 & 0.001 & -0.062163 & 0.000 \\
open & 0.237208 & 0.0104 & 0.0768197 & 0.000 & 0.0208476 & 0.028 \\
lngov & 0.0000318 & 0.998 & 0.332744 & 0.000 & -0.016674 & 0.211 \\
$W \times$ Ifi & -0.00018 & 0.342 & -0.001171 & 0.000 & -0.000531 & 0.137 \\
$W \times \operatorname{lnpgdp}$ & 0.0915499 & 0.000 & 0.0828646 & 0.000 & 0.0098369 & 0.711 \\
$W \times$ open & 0.0089339 & 0.642 & -0.343967 & 0.125 & 0.0081671 & 0.676 \\
$W \times \operatorname{lngov}$ & 0.0199772 & 0.468 & 0.0108475 & 0.426 & -0.087850 & 0.014 \\
$\rho$ & 0.2983711 & 0.001 & 0.2538189 & 0.017 & -0.279570 & 0.019 \\
$R^{2}$ & 0.7976 & & 0.6835 & & 0.7089 & \\
\hline
\end{tabular}


inclusive finance index has a significant negative impact on industrial upgrading in neighboring regions. The reason for the above phenomenon may be that the development of digital inclusive finance has promoted the optimization of resource allocation in the region, and in this process attracted resources from surrounding areas to gather locally to serve the region, leading to the industrial structure of the neighboring area. The upgrade is facing resource constraints. In the time-fixed effect model, the regression coefficient of per capita GDP on industrial structure upgrading is positive and significant. The reason for this may be that the higher the level of economic development in the region, the better it can provide optimized services for the upgrading of the region's industrial structure. In the three models, the coefficients of the cross-products of the per capita GDP and the spatial weight matrix are all positive. It shows that the economic development of this region promotes the upgrading of the industrial structure of the neighboring regions. The degree of opening up in the region has a positive and significant impact on the upgrading of industrial structure, but the product of opening up and the spatial weight matrix is not significant at the $10 \%$ level. This shows that the higher the degree of a region's external presence, the more it can promote the optimal allocation of resources in the region and thus have a positive impact on the upgrading of the industrial structure, but the impact on neighboring regions is not significant. In the time fixed effect model, the regression coefficient of government intervention on the upgrading of industrial structure is significantly positive, while in the dual fixed effect model, the crossover term of government intervention and the spatial weight matrix is significantly negative. This shows that government intervention in this region has a positive impact on the industrial structure, but it will inhibit the upgrading of the industrial structure in neighboring areas.

\subsection{Direct and Indirect Effects of Explanatory Variables}

Further study the spatial impact of IFI on the upgrading of industrial structure and its spatial effect, and calculate the direct and indirect effects of variables, as shown in Table 4. The digital inclusive finance index has a significant positive impact on the upgrading of the local industrial structure, and it has a negative

Table 4. IFI Spatial spillover effect estimation.

\begin{tabular}{cccc}
\hline Explanatory variables & Direct effect & Indirect effect & Total effect \\
\hline \multirow{2}{*}{ Ifi } & $0.0002844^{* *}$ & -0.0001352 & $0.0001491^{* *}$ \\
& $(0.015)$ & $(0.467)$ & $(0.048)$ \\
lnpgdp & $-0.04827^{* * *}$ & $0.1051319^{* * *}$ & $0.0566617^{*}$ \\
& $(0.000)$ & $(0.000)$ & $(0.057)$ \\
open & $0.0255763^{* *}$ & -0.0228471 & 0.484234 \\
& $(0.013)$ & $(0.392)$ & $(0.125)$ \\
lngov & 0.000735 & 0.0266526 & 0.0273876 \\
& $(0.957)$ & $(0.486)$ & $(0.488)$ \\
\hline
\end{tabular}


but not significant impact on the upgrading of the industrial structure in neighboring areas, and the total effect is a significant positive effect. It shows that digital inclusive finance can have a positive impact on the upgrading of the industrial structure by lowering the financial threshold and improving the efficiency of resource allocation. The overall impact of digital inclusive finance on the upgrading of the industrial structure is positive. The direct impact of per capita GDP on the upgrading of industrial structure is negative, the indirect effect is a significant positive effect, and the total effect of the upgrading of industrial structure is also a significant positive effect. The direct effect of the degree of opening to the outside world on the upgrading of the industrial structure is significantly positive, but the indirect and total effects are not significant. The direct, indirect, and total effects of government intervention on the upgrading of the industrial structure are all positive, but they are not significant.

\section{Conclusions and Policy Recommendations}

This paper combs the theoretical analysis of the relationship between digital inclusive finance and industrial structure upgrading, and believes that digital inclusive finance can promote the upgrading of industrial structure by lowering the financial threshold and improving the efficiency of resource allocation. Based on the panel data of 30 provinces, municipalities and autonomous regions from 2011 to 2018, this paper uses the spatial Dubin model to empirically analyze the impact of digital inclusive finance on the upgrading of industrial structure.

The empirical structure analysis results show that: First, digital inclusive finance can significantly promote the upgrading of the industrial structure in the region, and the impact on the surrounding areas is negative, but the overall effect is still positive. Second, the per capita GDP has a positive impact on the upgrading of the region's industrial structure, and the overall effect is also positive. Third, opening to the outside world will help the region's industrial structure upgrade, but the impact on neighboring areas is not significant. Fourth, government control can significantly promote the upgrading of the industrial structure in the region, but the indirect effects are not significant.

Based on the empirical structure, combined with China country's economic reality, this article puts forward the following suggestions:

First, promote and encourage the development of digital inclusive finance. The development of digital inclusive finance can significantly promote the upgrading of China country's industrial structure. It has a positive effect on the upgrading of the industrial structure by lowering financial thresholds, optimizing resource allocation, and promoting the improvement of the credit system. Therefore, we must continue to vigorously develop digital inclusive finance. It is necessary to make full use of digital technology to reduce information asymmetry in the financial market and reduce the business risks of digital inclusive finance. At the same time, traditional financial institutions are encouraged to implement digital inclusive finance business and promote the innovative devel- 
opment of digital inclusive finance so as to better serve China country's real estate industry structure which is upgraded.

Second, strengthen opening to the outside world according to local conditions. Opening to the outside world has a significant positive effect on the upgrading of the industrial structure. The increase in the degree of opening up can effectively promote the upgrading of China country's industrial structure; the total effect of the impact of per capita GDP on the upgrading of the industrial structure is positive. Therefore, the impact of economic development on the upgrading of the industrial structure cannot be ignored; enhanced supervision and government intervention can effectively promote the upgrading of the regional industrial structure, and reasonable government intervention can better optimize the allocation of local resources and guide economic development, thereby promoting the industrial structure upgrade. In additions, government supervision can also effectively manage the credit system-related issues that arise in the development of digital inclusive finance, optimize the credit supervision of digital inclusive finance, create a healthy development environment for digital inclusive finance, and better contribute to the development of digital inclusive finance.

\section{Conflicts of Interest}

The author declares no conflicts of interest regarding the publication of this paper.

\section{References}

[1] Xing, Y., Zhou, C.W. and Liu, H.E. (2015) The Utility and Realization of Inclusive Finance: Summary and Enlightenment. Research in International Finance, No. 11, 24-36.

[2] He, D.X. and Miao, W.L. (2015) Financial Exclusion, Inclusive Financial and the Construction of China's Inclusive Financial System. Finance and Trade Economics, No. 3, 5-16.

[3] Xie, P., Zhou, C.W. and Liu, H.E. (2015) The Basic Theory of Internet Finance. Financial Research, No. 8, 1-12.

[4] Bai, X.X. and Zhan, S. (2015) Re-Discussion on Inclusive Finance and Its Essential Features. Journal of Guangdong University of Finance and Economics, No. 3, 39-44.

[5] Sun, J. (2017) On Internet Finance, Technology Spillover and Total Factor Productivity of Commercial Banks. Market Modernization, No. 19, 113-114.

[6] Yuan, H.D. (2018) Research on the Impact of China's Inclusive Finance Development on the Upgrading of Industrial Structure. Shandong University of Technology, Zibo.

[7] Fu, Z.Q. and Huang, Y.P. (2018) The Heterogeneous Impact of Digital Finance on Rural Financial Demand: Evidence from China Household Finance Survey and Peking University Digital Inclusive Finance Index. Financial Research, No. 11, 68-84.

[8] Tang, W.J., Li, S. and Tao, Y.Q. (2019) Digital Inclusive Finance Development and Industrial Structure Upgrading: Empirical Evidence from 283 Cities. Journal of 
Guangdong University of Finance and Economics, No. 6, 35-49.

[9] Cao, K.Y. and Zhou, Y.F. (2019) The Impact of Digital Inclusive Finance on the Upgrading of Industrial Structure. Modern Business, No. 31, 81-84.

[10] Guo, F., Wang, J.Y., Wang, F., Kong, T. and Cheng, Z.Y. (2020) Measuring the Development of China's Digital Inclusive Finance: Index Compilation and Spatial Characteristics. Economics, No. 4, 1401-1418.

[11] Guo, W.L. and Chen, J.Y. (2020) Research on the Effect of Chinese Country's Digital Inclusive Finance Development and Industrial Structure Upgrading. Market Modernization, No. 11, 146-148.

[12] Su, R.G., Zhao, X.L. and Hu, X.X. (2020) Can Inclusive Finance Become a New Driving Force to Promote the Optimization and Upgrading of China's Industrial Structure?: Based on the Mechanism Analysis of Internet Development. Technical Economy, No. 4, 39-52. 